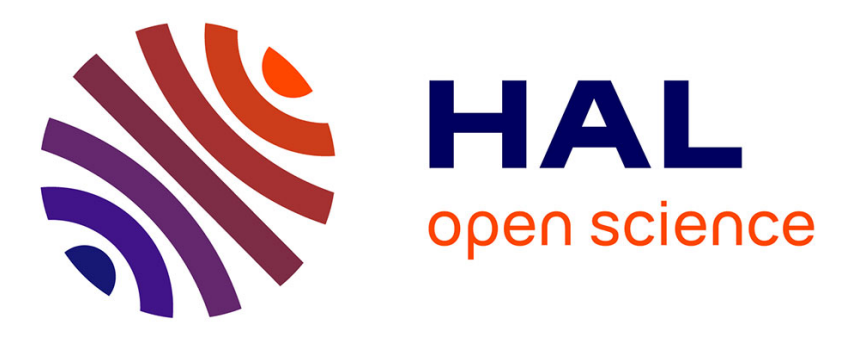

\title{
In vivo gene delivery in the mouse lung with lactosylated polyethylenimine, questioning the relevance of in vitro experiments
}

Stéphanie Grosse, G. Thévenot, Y. Aron, Eric Duverger, M. Abdelkarim, Annie-Claude Roche, Michel Monsigny, Isabelle Fajac

\section{To cite this version:}

Stéphanie Grosse, G. Thévenot, Y. Aron, Eric Duverger, M. Abdelkarim, et al.. In vivo gene delivery in the mouse lung with lactosylated polyethylenimine, questioning the relevance of in vitro experiments. Journal of Controlled Release, 2008, 132, pp.105-112. 10.1016/j.jconrel.2008.08.018 . hal-00512484

\author{
HAL Id: hal-00512484 \\ https://hal.science/hal-00512484
}

Submitted on 29 Sep 2021

HAL is a multi-disciplinary open access archive for the deposit and dissemination of scientific research documents, whether they are published or not. The documents may come from teaching and research institutions in France or abroad, or from public or private research centers.
L'archive ouverte pluridisciplinaire HAL, est destinée au dépôt et à la diffusion de documents scientifiques de niveau recherche, publiés ou non, émanant des établissements d'enseignement et de recherche français ou étrangers, des laboratoires publics ou privés.

\section{(c)(1)}

Distributed under a Creative Commons Attribution| 4.0 International License 


\title{
In vivo gene delivery in the mouse lung with lactosylated polyethylenimine, questioning the relevance of in vitro experiments
}

\author{
Stéphanie Grosse ${ }^{\mathrm{a}}$, Guiti Thévenot ${ }^{\mathrm{a}}$, Yolande Aron ${ }^{\mathrm{a}}$, Eric Duverger ${ }^{\mathrm{b}}$, Mohamed Abdelkarim ${ }^{\mathrm{a}}$, \\ Annie-Claude Roche ${ }^{\mathrm{b}}$, Michel Monsigny ${ }^{\mathrm{b}}$, Isabelle Fajac ${ }^{\mathrm{a}, *}$ \\ a Université Paris Descartes, Faculté de Médecine, AP-HP, Hôpital Cochin, EA 2511, Paris, France \\ ${ }^{\mathrm{b}}$ Glycobiologie, Centre de Biophysique Moléculaire, CNRS et Université d'Orléans, Orléans, France
}

Polyethylenimine (PEI) is an efficient vector for in vitro and in vivo gene transfer into respiratory cells. Glycosylated PEIs were shown to enhance in vitro gene transfer by favoring the complex entry into the airway cells. The aim of our study was to evaluate the in vivo efficiency of gene transfer mediated by glycosylated PEIs in the mouse lung and to determine the transfected cell type and the intracellular trafficking of the complexes. Upon nasal instillation in mice of complexes made with various glycosylated PEIs, a high luciferase activity was observed while the green fluorescent protein (GFP) expression was similar for all the vectors tested with few cells expressing GFP. Complexes made with lactosylated PEI were then labeled and their localization studied by confocal microscopy. In the lungs, large numbers of complexes were taken up by epithelial cell which were mostly alveolar cells. In the airways, complex uptake varied greatly, depending on the area observed. Eight hours upon nasal instillation and in contrast with the in vitro situation, a dissociation between the plasmid DNA and the lactosylated PEI was usually observed, leading to the plasmid mostly localized in lysosomes and the Lac-PEI localized in the nucleus. These results emphasize the need to engineer a plasmid able by itself to overcome the nuclear barrier and to quickly move to in vivo experiments to select the best carrier.

\section{Introduction}

Polyethylenimine (PEI) is one of the most efficient nonviral vectors for in vitro and in vivo gene delivery [1,2]. Like other synthetic vectors, PEI provides high and easy compaction of plasmid DNA. Its chemical structure is an added advantage. Every third atom is a potentially protonable amino nitrogen that allows a "proton sponge effect" leading to an endosomal exit of plasmid/PEI complexes taken up by the cells [3,4]. PEI has been successfully tested for gene transfer into a number of organs and it was found to have limited toxic or immune effects [1,2]. It is mainly available in two forms, a linear $22 \mathrm{kDa}$ and a branched $25 \mathrm{kDa}$ form. They have both been studied for gene transfer into the respiratory tract. They were shown to be efficient vehicles for gene transfer into respiratory epithelial cells in vivo with higher efficiency than that of cationic lipids $[5,6]$. However, the efficiency was highly dependent of the physiochemical properties of plasmid/PEI complexes and of biological phenomena which are not yet fully

\footnotetext{
* Corresponding author. Lab. Physiol. Respir., Faculté Paris Descartes, site Cochin, 24 rue du Fg St-Jacques, 75679 Paris Cedex 14, France. Tel.: +33 1444123 30; fax: +33144 412333.

E-mail address: ifajac@cochin.univ-paris5.fr (I. Fajac).
}

understood. Many studies were devoted to optimize the formulations of complexes made with PEI and the routes of delivery such as intravenous, aerosol or intranasal delivery [7-13]. The transfected cell types have also been studied. After intratracheal administration, linear PEI $22 \mathrm{kDa}$ mainly transfected the alveolar regions and the distal tract of the bronchial tree, whereas branched $25 \mathrm{kDa}$ PEI allowed gene transfer into the bronchial cells [5]. Unlike in vitro studies which have been largely devoted to describe the intracellular trafficking of the plasmid after its uptake by the cell $[14,15]$, the intracellular route of the plasmid after its uptake by the cell in vivo is unknown.

To promote specific cellular uptake of complexes and hopefully efficient intracellular trafficking, we have substituted the branched $25 \mathrm{kDa}$ PEI with sugar residues [16]. Because our ultimate goal is cystic fibrosis gene therapy, we have studied various glycosylated PEIs in vitro in airway epithelial cells and showed that lactosylated PEI (LacPEI) was the most efficient glycosylated PEI for gene transfer [16]. It was also less toxic than unsubstituted PEI [17]. Therefore, we wanted to assess the potential of glycosylated PEIs as vectors for in vivo gene transfer and studied their efficiency after nasal instillation in mice. To further our understanding of glycosylated PEI-mediated gene transfer in vivo, the plasmid and the vector were independently labeled in order to identify the cells able to take up the complexes and to study the intracellular trafficking of the complexes. 


\section{Materials and methods}

\subsection{Polyethylenimine derivatives and gene transfer procedure}

Five percent of the amino groups of PEI ( $25 \mathrm{kDa}$, branched polymer; Sigma, St Louis, MO, USA) were substituted by a thiocarbamoyl residue of either $\beta$-D-Lac ( $\beta$-D-lactose), $\beta$-D-Glc ( $\beta$-D-glucose) or $\alpha$-D-Man $(\alpha-$ D-mannose). Briefly, to a solution of PEI dissolved in water $(10 \mathrm{mg} / \mathrm{ml})$, glycosyl phenylisothiocyanate $(12 \mu \mathrm{mol})$ dissolved in $1 \mathrm{ml}$ of a $1: 1$ ethanol/water mixture was added and the solution was stirred for $30 \mathrm{~min}$ at room temperature. Under such conditions, the free glycosyl phenylisothiocyanate was no longer detectable upon thin-layer chromatography on silica gel plates using a 100:30:10:10:3 ethanol/ water/n-butanol/pyridine/acetic acid mixture. Upon removal of the ethanol, the water solution was freeze-dried [16]. Fluoresceinconjugated lactosylated PEI (Lac-PEI) was prepared by using fluorescein isothiocyanate as previously described [16].

The requested amount of glycosylated PEI or unsubstituted PEI (25 kDa, branched form or $22 \mathrm{kDa}$, linear form, ExGen ${ }^{\circledR}$ ) was mixed with 50,100 or $150 \mu$ of the plasmid in a final volume of $150 \mu \mathrm{l}$ of various formulation solutions in order to reach the requested $\mathrm{N} / \mathrm{P}$ ratio (from 2.5 to 15). The plasmids used were pCMVLuc (pUT 650, $5.15 \mathrm{~kb}$ ) (Cayla, Toulouse, France) and pCMVGFP (pGFPemd-cmv; $4.80 \mathrm{~kb}$ ) (Packard, Meriden, CT, USA) which include genes encoding the firefly luciferase and the green fluorescent protein (GFP), respectively, under the control of the human cytomegalovirus promoter.

Five-week-old female BALB/c mice (Harlan, Gannat, France) were briefly anesthetized with halothane (Belamont, Paris, France) and instilled intranasally with $150 \mu$ of complexes using a pipetman (P200 Gilson). At the time of the gene transfer analysis step, the animals were killed by an intraperitoneal overdose of pentobarbital. The circulation was perfused with $4 \%$ paraformaldehyde via the right ventricule and the lungs and trachea were dissected and kept on ice up to their analysis. The study was performed in accordance with the European Community Guidelines and complied with the procedures of our IFR (Institut Fédératif de Recherche Alfred Jost).

\subsection{Gene expression}

When luciferase expression was studied, the lungs and trachea were disrupted in a lysis buffer $(8 \mathrm{mM} \mathrm{MgCl} 2,1 \mathrm{mM}$ EDTA, $1 \mathrm{mM}$ dithiothreitol, $15 \%$ glycerol, $1 \%$ Triton $\mathrm{X}-100,25 \mathrm{mM}$ Tris $\mathrm{HCl}$ at $\mathrm{pH} 7.8$ ) using an Ultra-Turrax T25 homogenizer (Fischer Bioblock Scientific, Strasbourg, France). The cell lysate was centrifuged for $10 \mathrm{~min}$ at $10,000 \mathrm{~g}$ and luciferase gene expression was measured by luminescence according to de Wet et al. [18]. The luminescence generated upon automatic addition of $150 \mu \mathrm{l}$ of $167 \mu \mathrm{M}$ luciferin dissolved in water was recorded in duplicate samples for $10 \mathrm{~s}$ by using a luminometer (Lumat LB 9501, Berthold, Wildbach, Germany). The luminescence is reported as relative light units (RLU). Protein concentrations in each sample were determined using the bicinchoninic acid (BCA) colorimetric method modified according to Hill and Straka [19]. Results are expressed as RLU per mg of proteins.

When the pCMVGFP plasmid was used, the lungs and trachea were fixed in $4 \%$ paraformaldehyde and frozen in OCT compound over liquid nitrogen. Seven- $\mu \mathrm{m}$ thick cryosections were cut, mounted in vectashield solution (Vector Laboratories, Burlingame, CA, USA) and examined for GFP expression with a Leitz epifluorescence microscope (Leica, Rueil-Malmaison, France). Lung and airway morphology was examined on adjacent sections stained with hematoxylin and eosine following standard procedures.

\subsection{Complex localization in airways and lungs}

Mice were instilled with $150 \mu$ of complexes made of pCMVLuc $(100 \mu \mathrm{g})$ and fluoresceinylated Lac-PEI $(\mathrm{N} / \mathrm{P}=12.5)$ in a $5 \%$ glucose solution. Mice were killed $48 \mathrm{~h}$ later and the dissected lungs and trachea fixed in $4 \%$ paraformaldehyde. Tissue cryosectioned $7-\mu \mathrm{m}$ thick slides were mounted in Vectashield mounting medium with propidium iodide (Vector laboratories) and examined with a Leitz epifluorescence microscope (Leica). In order to determine in which cells complexes were localized, tissue cryosectioned 7- $\mu \mathrm{m}$ thick slides were incubated for $10 \mathrm{~min}$ with $0.1 \mathrm{M}$ glycine in phosphate-buffered saline (PBS), for 15 min with $0.2 \%$ mouse serum albumin and $0.2 \%$ tween in PBS and then stained using antibodies raised against mouse surfactant protein B (Chemicon, Temecula, CA, USA) or F4/80 antigen (Abcam, Cambridge, UK) for alveolar type II cells or alveolar macrophages, respectively. Sections were then incubated with Cy5-conjugated secondary antibodies (Jackson ImmunoResearch, West Grove, PA, USA), mounted in Vectashield solution and examined with a TCS SP2 AOBS Leica confocal system mounted on a Leica DMIRE2 inverted microscope.

a

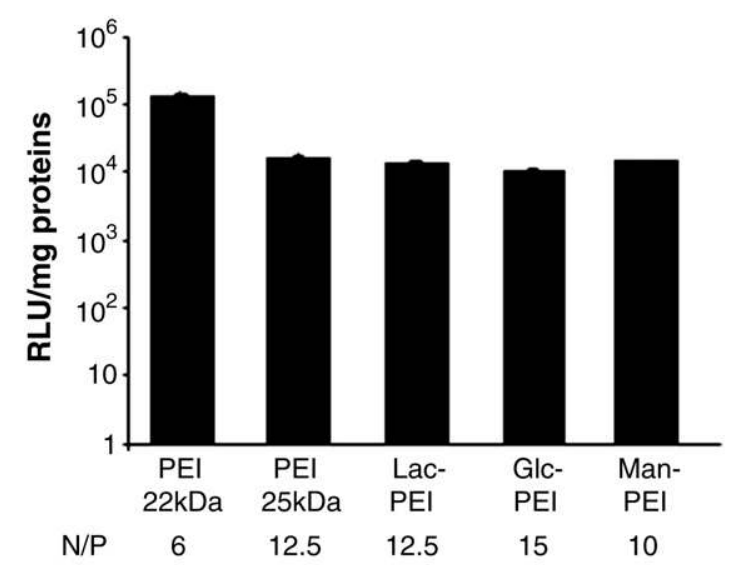

b

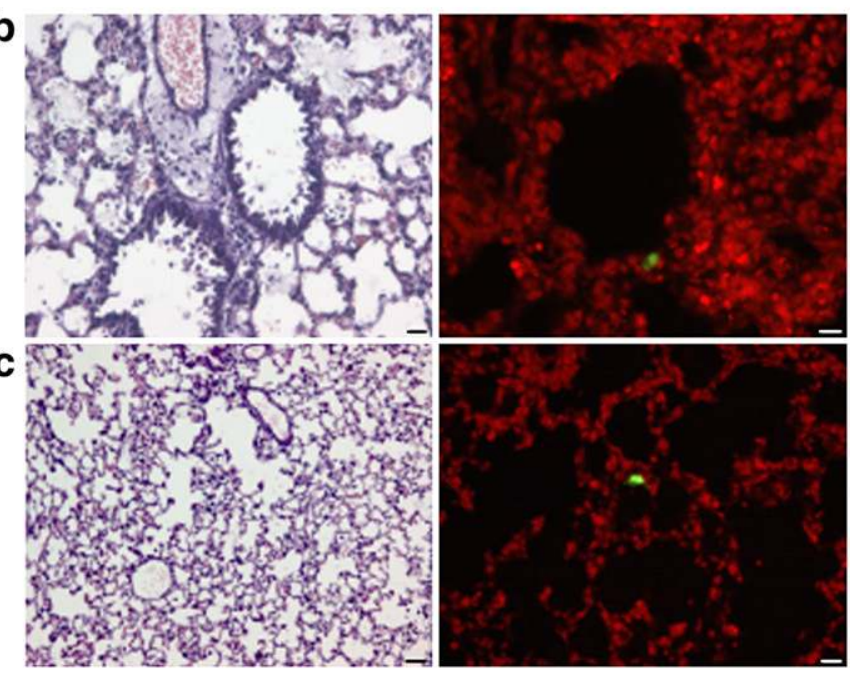

Fig. 1. Gene transfer with cationic polymers into the mouse lung. a: Optimal PEImediated luciferase expression in the mouse lung. The requested amount of cationic polymer, i.e. $22 \mathrm{kDa}$ linear PEI, $25 \mathrm{kDa}$ branched PEI, lactosylated PEI (Lac-PEI), glucosylated PEI (Glc-PEI) and mannosylated PEI (Man-PEI), was mixed with $100 \mu \mathrm{gg}$ of a plasmid encoding the firefly luciferase protein in a $5 \%$ glucose solution. Complexes were administered intranasally to BALB/c mice and $48 \mathrm{~h}$ later, the animals were killed, the lungs and trachea dissected and luciferase expression studied. (the optimal N/P ratio is indicated). b and c: Lac-PEI-mediated GFP expression in the mouse bronchi and lung, respectively. A plasmid encoding the GFP protein was complexed with Lac-PEI $(\mathrm{N} / \mathrm{P}=6)$ and administered intranasally to mice. Forty-eight hours later, mice were killed, the lungs and trachea dissected, fixed and cryosectioned. GFP expression appears green and the cell nuclei stained with propidium iodide, red in the right-hand panel (b: bar $=10 \mu \mathrm{m}$; c: bar $=20 \mu \mathrm{m})$. Adjacent sections stained with hematoxylin and eosine are shown on the left-hand panel (b: bar $=20 \mu \mathrm{m}$; c: bar $=100 \mu \mathrm{m}$ ). 


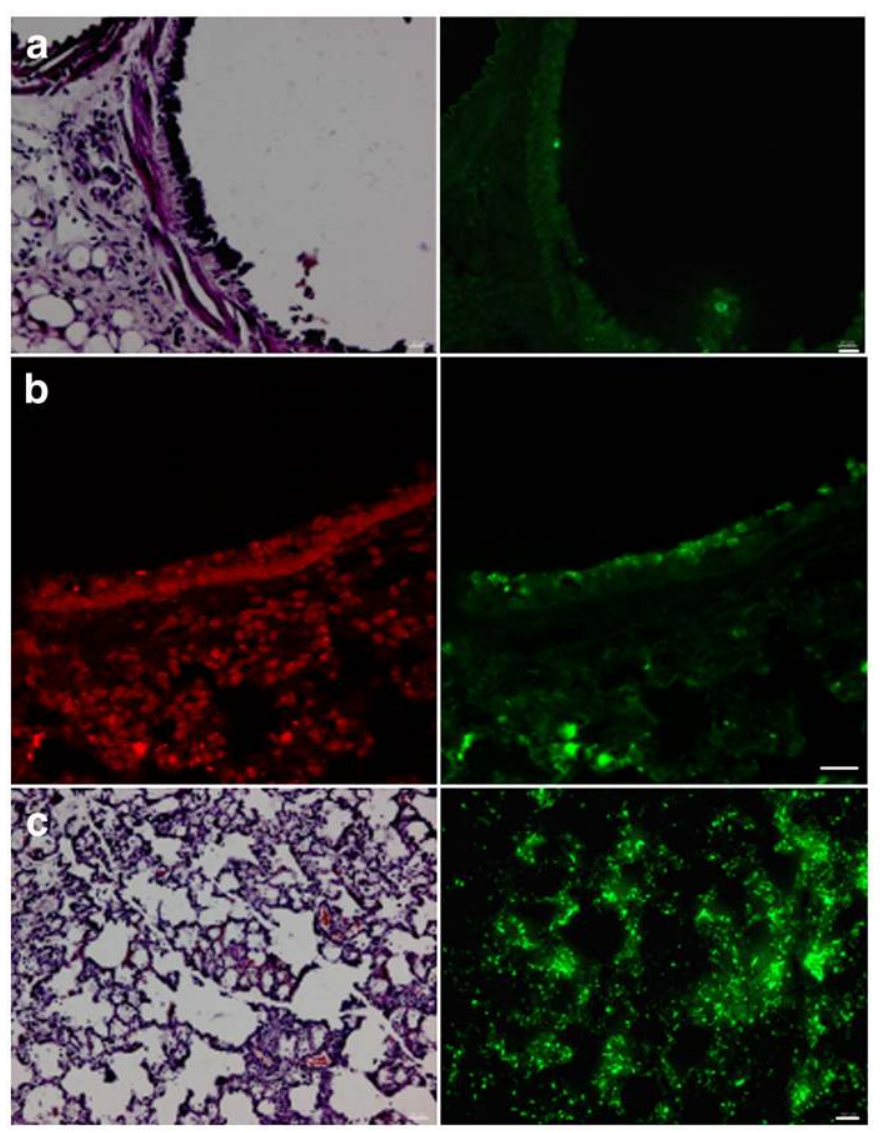

Fig. 2. Distribution of Lac-PEI complexes in the mouse bronchi (a and b) and lung (c). Complexes were made with fluoresceinylated Lac-PEI and a plasmid encoding the firefly luciferase protein and instilled intranasally into mice. Animals were killed $48 \mathrm{~h}$ later and the biodistribution of complexes was analyzed on cryosectioned slides. The left-hand panels show tissue sections stained with hematoxylin and eosin ( $a$ and c) or with propidium iodide (b). The right-hand panels show the same area of an adjacent section and the fluoresceinylated complexes which appear green: distribution in the airway epithelium was uneven, from very few (a) to numerous complexes (b). In contrast, numerous Lac-PEI complexes were seen inside the lungs (c). (a and b: bar $=20 \mu \mathrm{m}$; c: bar $=100 \mu \mathrm{m})$.

\subsection{Intracellular trafficking of complexes}

The pCMVLuc plasmid was biotinylated using the FastTag nucleic acid labeling system (Vector Laboratories). Mice were instilled with $150 \mu \mathrm{l}$ of complexes made of biotinylated PCMVLuc and fluoresceinylated Lac-PEI $(\mathrm{N} / \mathrm{P}=12.5$ in a $5 \%$ glucose solution). To verify if the trafficking was modified by the labeling of plasmid or Lac-PEI, some mice were also instilled with complexes made with unlabeled pCMVLuc and fluoresceinylated Lac-PEI or with complexes made with biotinylated pCMVLuc and unlabeled Lac-PEI. Three, 8 or $24 \mathrm{~h}$ later, the animals were killed and the lungs were excised, fixed in $4 \%$ paraformaldehyde and cryosectioned in $7-\mu \mathrm{m}$ thick sections in order to study the intracellular localization of complexes. Slides were incubated for $10 \mathrm{~min}$ with $0.1 \mathrm{M}$ glycine in PBS, for $15 \mathrm{~min}$ with $0.2 \%$ mouse serum albumin and $0.2 \%$ tween in PBS and then the biotinylated plasmid DNA was labeled with a streptavidin conjugate (Molecular Probes, Eugene, OR, USA). Lysosomes were immunolabeled with rat antibodies raised against the lysosomal-associated membrane protein 1 (LAMP-1) (BD Biosciences, San Jose, CA, USA) followed by $Q \operatorname{dot} \AA 605$ anti-rat antibodies (Molecular Probes). The nuclear membrane was immunolabeled with rabbit antibodies directed against lamin A/C (Cell Signaling Technology, Danvers, MA, USA) followed by Cy5-conjugated anti-rabbit antibodies (Jackson Immu-
noResearch). The localizations of plasmid DNA and Lac-PEI were then analyzed by confocal microscopy. Serial sections collected at increments of $0.5-\mu \mathrm{m}$ thick were used to define the intracellular localization of plasmid DNA/lactosylated PEI complexes. The images obtained were processed with ImageJ, 1.34s software.

\section{Results}

\subsection{Gene transfer efficiency}

The efficiency of gene transfer into the mouse lungs and airways was studied for five vectors: $22 \mathrm{kDa}$ PEI (linear form, ExGen ${ }^{\circledR}$ ), $25 \mathrm{kDa}$ PEI (branched from) and three glycosylated branched PEI: lactosylated PEI (Lac-PEI), glucosylated PEI (Glc-PEI) and mannosylated PEI (Man$\mathrm{PEI}$ ). These sugar residues were chosen on the basis of their efficiency for in vitro gene transfer into airway epithelial cells (Lac-PEI and GlcPEI) or of their high uptake by these cells (Man-PEI) [16].

Various conditions of gene transfer were studied for each vector: the plasmid dose varied from 50 to $150 \mu \mathrm{g}$, the N/P ratio from 2.5 to 15 , the formulation solutions were water, $9 \%$ $\mathrm{NaCl}$ or $5 \%$ glucose and the time of study 24 or $48 \mathrm{~h}$ after nasal instillation. For all the vectors tested, no luciferase activity was observed in the trachea. In the lungs, for all $25 \mathrm{kDa}$ PEI derivatives, the highest luciferase activity was observed $48 \mathrm{~h}$ after complex instillation and with complexes generated in a $5 \%$ glucose solution, using $100 \mu \mathrm{g}$ of plasmid (Fig. 1a). For each PEI derivative, the optimal N/P ratio was in the 10 to 15 range. A 10 -fold higher luciferase activity was observed with complexes made with linear $22 \mathrm{kDa}$ PEI ( $100 \mu$ of plasmid, $\mathrm{N} / \mathrm{P}=6$ in $5 \%$ glucose solution), as compared with that obtained with branched $25 \mathrm{kDa}$ PEI derivatives $(p<0.01$, Mann-Whitney $U$-test). However, when GFP expression was studied, it was similar for all
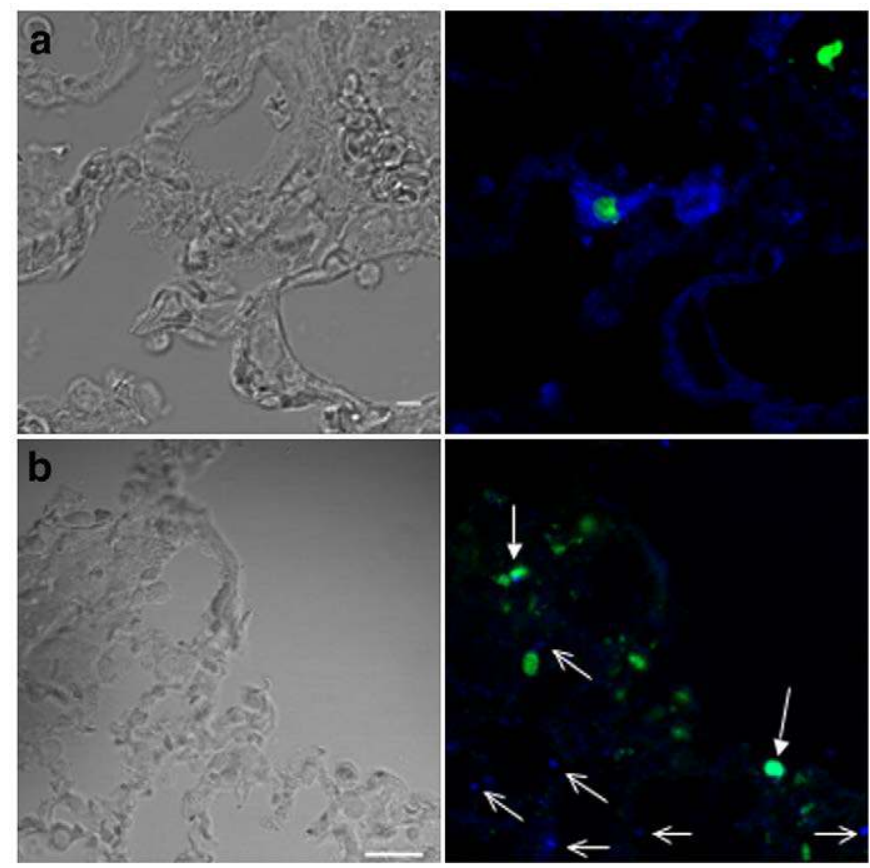

Fig. 3. Determination of cells that have taken up Lac-PEI complexes. Complexes were made with fluoresceinylated Lac-PEI and a plasmid encoding the firefly luciferase protein and instilled intranasally into mice. Animals were killed $48 \mathrm{~h}$ later and alveolar macrophages (a) or alveolar type II cells (b) were immunolabeled on lung cryosectioned slides. a: On the left-hand panel, phase-contrast image of cells; on the right-hand panel, merged image of cells with two alveolar macrophages (in blue) and of fluoresceinylated complexes (in green): complexes were occasionally observed in alveolar macrophages (in the middle), but some were outside macrophages (in the upper right corner). (bar $=5 \mu \mathrm{m}$ ) (b) On the left-hand panel, phase-contrast image of cells; on the right-hand panel, merged image of alveolar type II cells (in blue, open arrows) and of fluoresceinylated complexes (in green). Closed arrows show complexes in alveolar type II cells. (bar $=20 \mu \mathrm{m})$. 
the vectors tested: few cells expressed GFP and they were more often observed in the lungs than in the airway epithelium (Fig. 1b and c).

When mice received only $5 \%$ glucose, no death was registered. Depending on the vectors, the number of mice studied varied from 20 for Man-PEI to 40 for $22 \mathrm{kDa}$ PEI and 115 for Lac-PEI. Mice were occasionally found dead in the $24 \mathrm{~h}$ following nasal instillation. The mortality rate registered $24 \mathrm{~h}$ after administration was $7.1 \%$ for $22 \mathrm{kDa}$ PEI, 8.6\% for $25 \mathrm{kDa}$ PEI, $0.8 \%$ for Lac-PEI, $2.7 \%$ for Glc-PEI and $10.5 \%$ for Man-PEI. Deaths were usually observed when complexes at the highest $\mathrm{N} / \mathrm{P}$ ratios have been administered. With all the investigated vectors at the most efficient complex formulation, the lung morphology was found to be normal: specially, neither oedema nor inflammatory cell recruitment could be observed (Fig. 1b and c).

\subsection{Complex localization in airways and lungs}

In order to further our understanding of glycosylated PEImediated gene transfer in vivo, we labeled one glycosylated PEI and studied the localization of the complexes and their intracellular trafficking. Since no glycosylated PEI was clearly more efficient than the others, we chose to study Lac-PEI because it was the most efficient one in vitro and we had studied its in vitro intracellular trafficking [17]. Complex distribution into the epithelium of large airways was uneven (Fig. 2a and b). This was not dependent on the mouse studied, nor on some localization in the airways. In contrast, numerous Lac-PEI complexes were always observed in alveolar spaces (Fig. 2c). To identify cells in

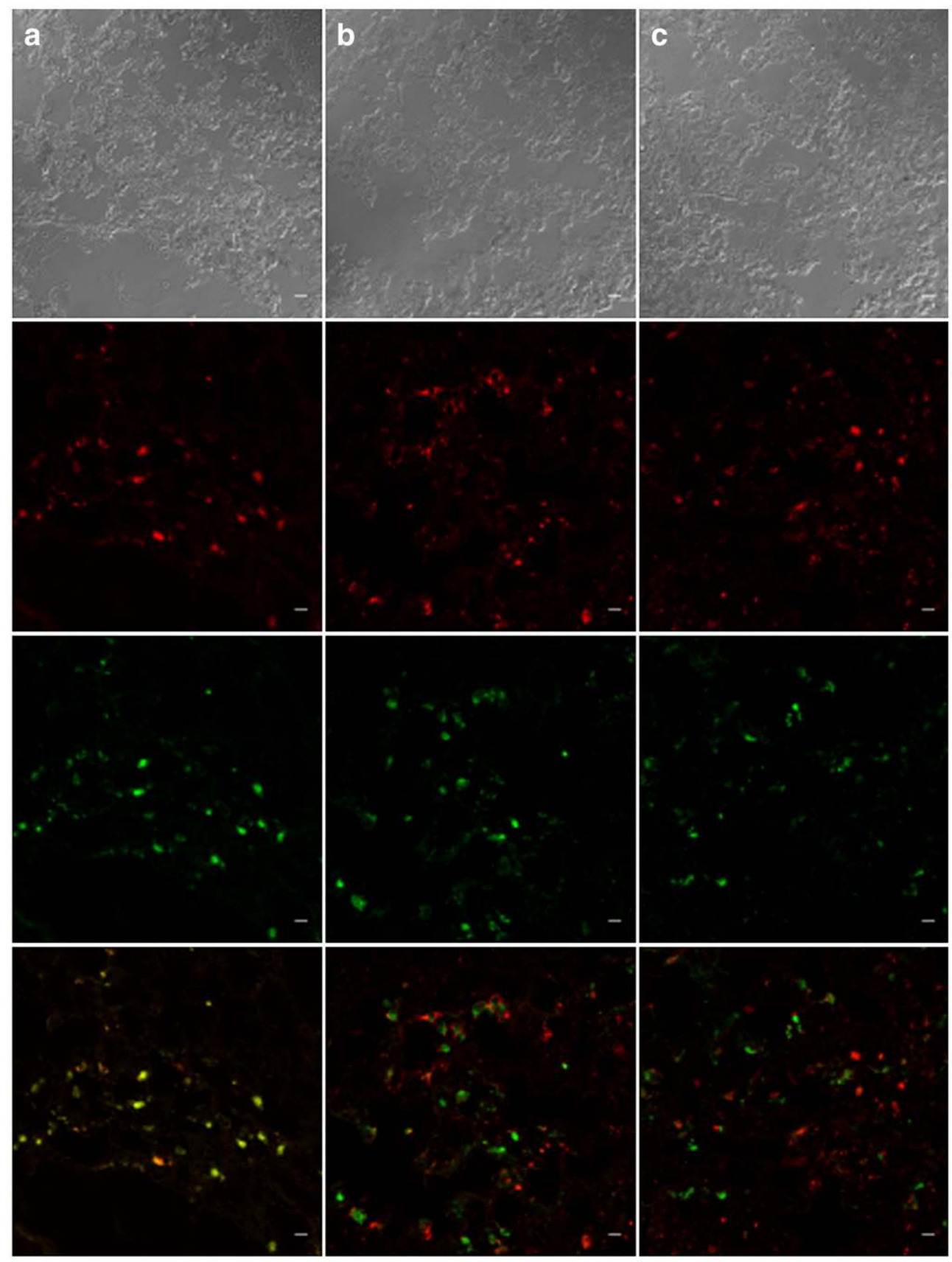

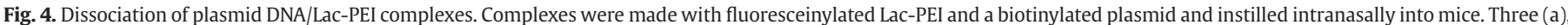

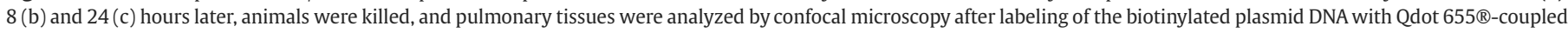

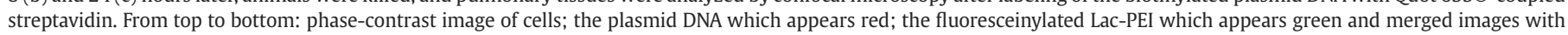
complexes that appear yellow (bar $=10 \mu \mathrm{m})$. 

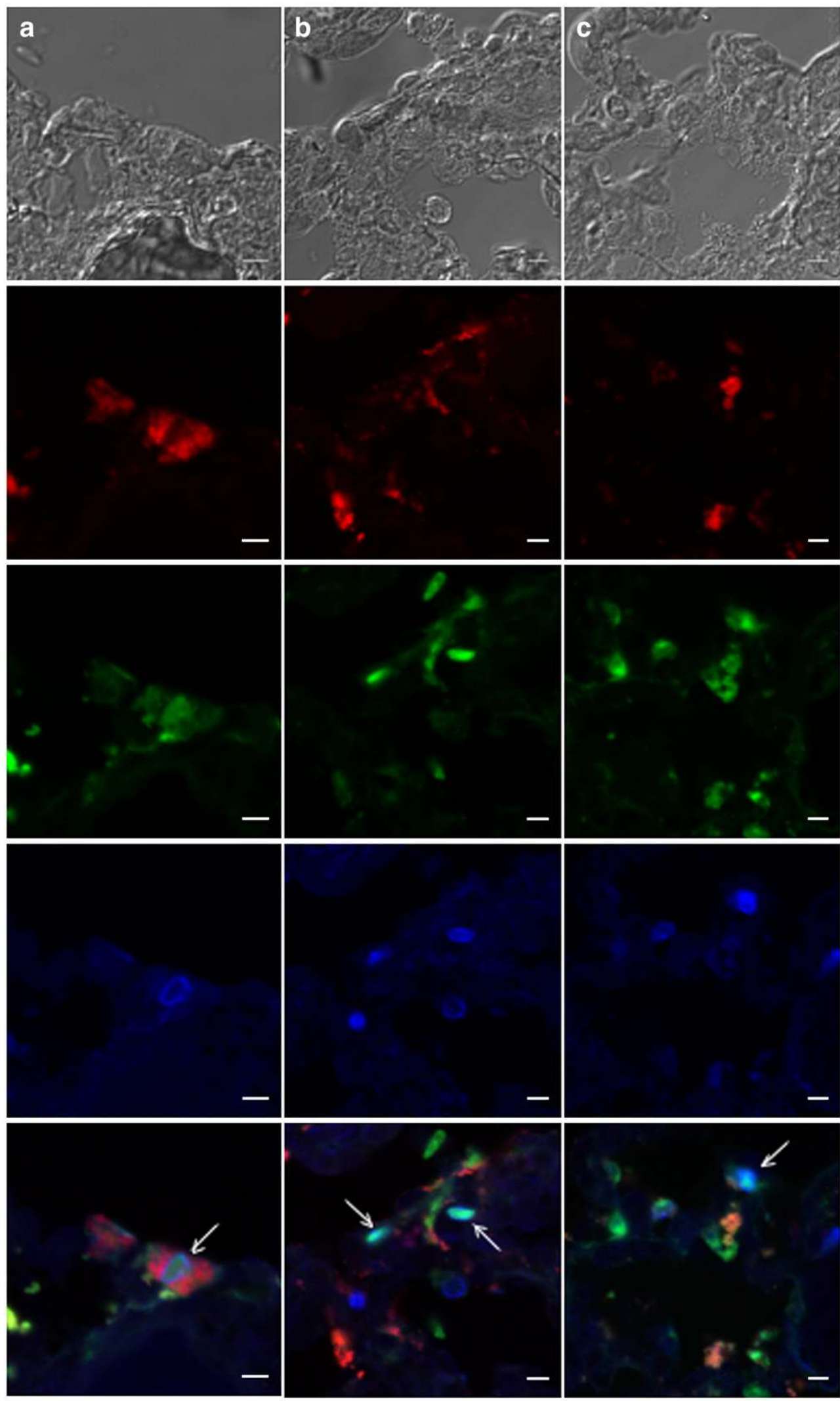

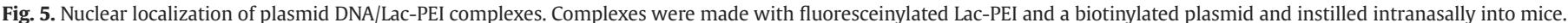

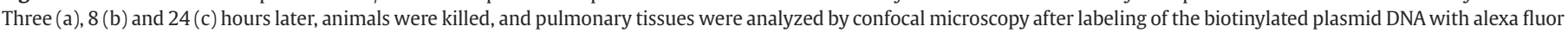

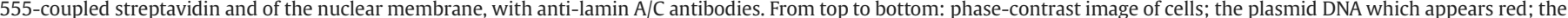

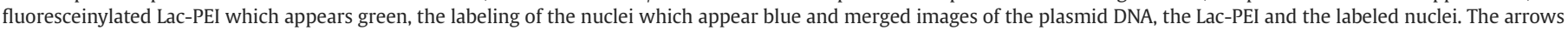
show the nuclear localization of Lac-PEI (bar $=5 \mu \mathrm{m})$. 
which complexes were present, alveolar type II cells and alveolar macrophages were labeled. Complexes were only occasionally observed in alveolar macrophages (Fig. 3a) and in alveolar type II cells (Fig. 3b).

\subsection{Intracellular trafficking of complexes}

Despite numerous complexes in alveolar cells, the efficiency of gene transfer was quite low, with only a limited number of cells expressing GFP. This suggested that the intracellular trafficking of complexes was inefficient.

In order to evaluate whether the plasmid DNA remained as a complex or as a vector-free molecule within the cell, complexes were made with a biotinylated plasmid and fluoresceinylated Lac-PEI. Three hours upon nasal instillation, the plasmid DNA was always observed as a complex with Lac-PEI (Fig. 4a). Eight and $24 \mathrm{~h}$ upon nasal instillation, dissociation between the plasmid DNA and Lac-PEI was observed for most complexes (Fig. 4b and c).

The nuclear localization of the biotinylated plasmid DNA and the fluoresceinylated Lac-PEI was studied after labeling the internal nuclear membrane. Three hours upon nasal instillation, a nuclear localization was seldom observed and mostly occurred for Lac-PEI (Fig. 5a). Eight hours upon nasal instillation, Lac-PEI was clearly localized inside the nucleus while the plasmid was not (Fig. 5b). Twenty-four hours upon nasal instillation, both plasmid DNA and LacPEI could be observed in the nucleus, but to a low extent (Fig. 5c). The nuclear localization of plasmid DNA and Lac-PEI was similar when the mice that have received complexes made with unlabeled pCMVLuc and fluoresceinylated Lac-PEI or complexes made with biotinylated pCMVLuc and unlabeled Lac-PEI were studied.

The lysosomal localization of the biotinylated plasmid DNA and the fluoresceinylated Lac-PEI was then studied, lysosomes being labeled with an antibody recognizing LAMP-1, a lysosomal glycoprotein. Three hours upon nasal instillation, complexes were very seldom observed in lysosomes. Eight hours upon nasal instillation, lysosomal localization was frequently observed and mostly occurred for the plasmid DNA (Fig. 6a). Twenty-four hours upon nasal instillation, the localization in lysosomes was low (Fig. 6b). The lysosomal localization of plasmid DNA and Lac-PEI was similar when the mice that have received complexes made with unlabeled pCMVLuc and fluoresceinylated Lac-PEI or complexes made with biotinylated PCMVLuc and unlabeled Lac-PEI were studied.

\section{Discussion}

Several authors have demonstrated that unsubstituted linear $22 \mathrm{kDa}$ PEI or branched $25 \mathrm{kDa}$ PEI are suitable vehicles for gene transfer into respiratory epithelial cells in vivo in mice with a higher efficiency than cationic lipids [5,6]. In vitro, the presence of sugar residues on glycosylated PEI allowed the targeting of cell-surface sugar-specific receptors leading the complexes to bind the cell surface with a higher efficiency and to be more taken up inside the cells [16]. Moreover, in vitro in airway epithelial cells, Lac-PEI was less toxic and more efficient than unsubstituted PEI [17]. We here show for the first time that glycosylated PEIs are as efficient as

Fig. 6. Lysosomal localization of plasmid DNA/Lac-PEI complexes. Complexes were made with fluoresceinylated Lac-PEI and a biotinylated plasmid and instilled intranasally into mice. Eight (a) and 24 (b) hours later, animals were killed, and pulmonary tissues were analyzed by confocal microscopy after labeling of the biotinylated plasmid DNA with Qdot $655 \circledR$-coupled streptavidin and lysosomes, with anti-LAMP1 antibodies. From top to bottom: phase-contrast image of cells; the plasmid DNA which appears red; the fluoresceinylated Lac-PEI which appears green; the labeling of lysosomes which appear blue and merged images of the plasmid DNA, the Lac-PEI and the labeled lysosomes. The arrows show the lysosomal localization of the plasmid DNA (bar $=10 \mu \mathrm{m}$ ). unsubstituted PEI for in vivo gene transfer into the mouse lungs upon nasal instillation and that they display low toxicity. Moreover, we have studied the intracellular trafficking of complexes upon nasal

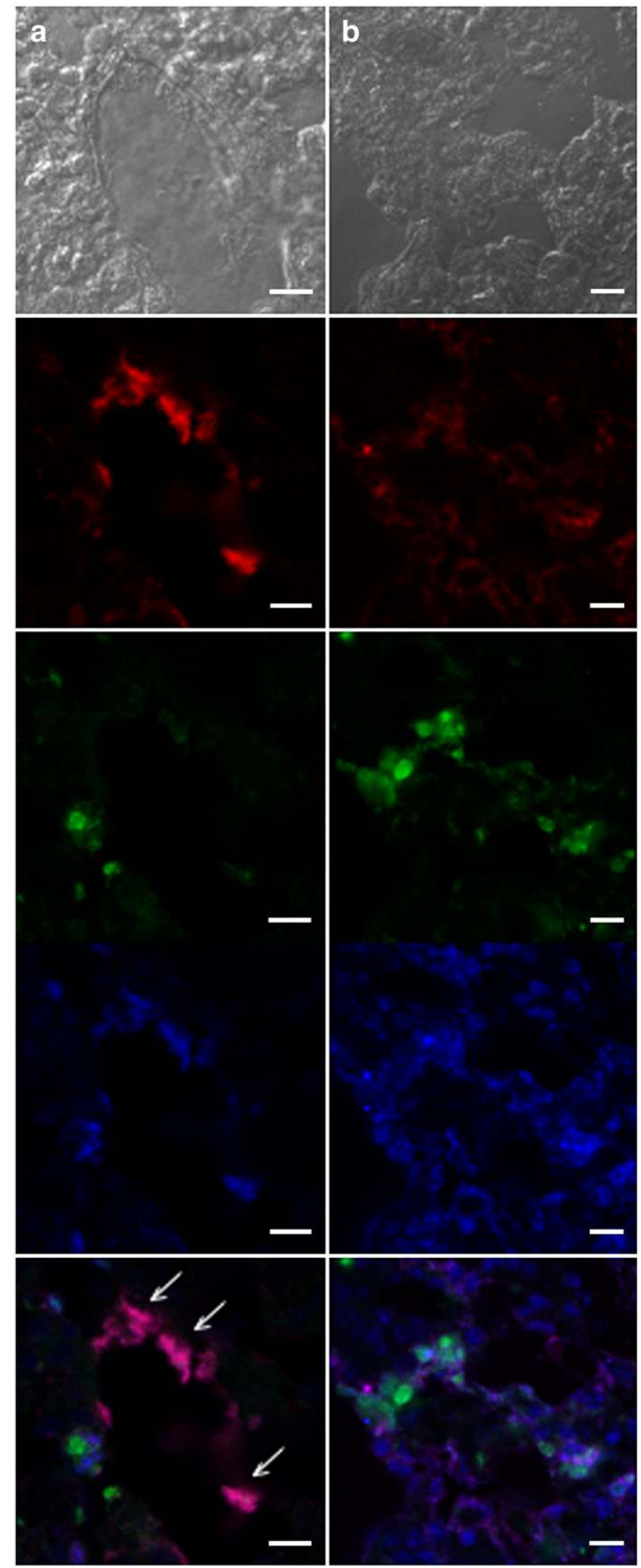


instillation and showed that it is quite different than the one described in vitro.

The level of luciferase activity we obtained was similar to that described by Bragonzi et al. [5] upon intratracheal instillation in mice of complexes made with unsubstituted PEI. The optimal formulations we found (complexes generated in a $5 \%$ glucose solution, with $100 \mu \mathrm{g}$ of plasmid and an N/P ratio between 10 and 15) are those described by others $[2,20]$. Glycosylated PEIs made with branched $25 \mathrm{kDa}$ PEI were as efficient as the unsubstituted polymer and, in contrast with in vitro experiments, there was no difference in the efficiency of the various glycosylated polymers. This might be due to differences in the physicochemical properties of the complexes made for in vivo administration as compared with those made for in vitro experiments: for in vivo experiments, the amounts of plasmid (and of PEI derivative) were higher, the N/P ratios were sometimes a little higher too and this might lead to high nonspecific uptake. However, despite a luciferase activity between $10^{4}$ and $10^{5} \mathrm{RLU} / \mathrm{mg}$ proteins, the number of GFP-expressing cells was quite low for all PEI derivatives. This discrepancy between relatively high levels of luciferase expression and low numbers of GFPexpressing cells has been previously reported [21]. It was attributed to either a GFP expression below the detection limit in any given cell, to a differential expression level of the luciferase and GFP genes present in the plasmid, or to a high level of luciferase expression in a few lung cells. In any case, although direct visualisation of GFP expression is simple and allows the localization of gene expression, more sensitive methodologies for the detection of nonviral in vivo gene transfer is needed.

Despite numerous reports concerning the use of PEI for nonviral gene transfer into the mouse lung [1,2], few have identified the type of the transfected cell upon nasal instillation $[5,10,21,22]$ and, to our knowledge, none has investigated the intracellular trafficking of the plasmid DNA. We chose to further study the Lac-PEI vector because it was the most efficient glycosylated PEI for in vitro gene transfer into airway epithelial cells [16]. By labeling the complexes and some respiratory cell types, we have determined that macrophages which are the first line of defence in the lungs do not take up most of the complexes. In contrast, complexes were observed in epithelial cells. However, these were mostly epithelial alveolar cells which are of poor interest for cystic fibrosis gene therapy. The uptake of complexes by the airway cells was very uneven, from very few to numerous cells having taken up the complexes in the same mouse. This uneven distribution has been reported after nasal instillation of complexes [21]. Aerosol delivery would probably have yielded more relevant results for cystic fibrosis gene therapy since gene expression is higher after nebulization than after nasal instillation and gene expression has been reported to be mainly localized in the bronchial epithelium of large airways $[10,12]$. Although the complex localization was not the one that could be expected to be the most appropriate for cystic fibrosis gene therapy, the number of complexes that have been taken up by the alveolar or the bronchial epithelial cells was high. This shows that although these complexes were positively charged $(\mathrm{N} / \mathrm{P}=12.5)$ and likely to interact with the negatively charged macromolecules of the mucus lining the airways and of the surfactant lining the alveolar space, it did not prevent a large quantity of complexes to access the epithelial cells. Besides the targeting of sugar receptors, it may be hypothesized that the sugar ligand has an additional effect of shielding positive charges.

A large number of Lac-PEI complexes were taken up by the cells. However, a low gene transfer efficiency was observed. It suggested that an inefficient intracellular trafficking occurred in vivo as it is the case in vitro $[17,23]$. We therefore studied the intracellular trafficking of Lac-PEI complexes in vivo after nasal instillation. In vitro, in various epithelial cell types including airway epithelial cells, we [17] and others [24-27] have reported that when complexed with a PEI derivative, a plasmid enters the nucleus mostly as a complex. We here show that it is not the case in vivo and that an early dissociation of the complex occurs, leading to a possible degradation of the plasmid and to different intracellular trafficking for the plasmid and the vector. While the small Lac-PEI enters the nucleus, the plasmid is mostly localized in lysosomes where it will finally be degraded. These results partly explain the low numbers of GFP-expressing cells that we found. They emphasize the need to study the different steps of gene transfer in the most in vivo appropriate models, since the mechanisms described in vitro in various cell lines are likely to be very different than the ones that occur in vivo. Finally, these results point out the need to engineer a compacted plasmid able by itself to target the nucleus. In this event, gene transfer would be a multiple step process with a vector acting as a Trojan horse, able to complex the plasmid, to target the cells of interest and to favor an endosomal exit. After dissociation between the plasmid and its vector, the engineered plasmid would then enter the nucleus to be transcribed.

In conclusion, we have shown that glycosylated PEIs are as efficient as unsubstituted $22 \mathrm{kDa}$ linear or $25 \mathrm{kDa}$ branched PEI for in vivo gene transfer into the mouse lungs and that transfected cells are mostly epithelial cells. However, the number of transfected cells was lower than that of cells having taken up the complexes. This was mostly due to an inefficient intracellular trafficking of complexes. While in vitro, complexes mostly stayed in an associated form during their intracellular trafficking, in vivo, complexes rapidly dissociated impeding an efficient nuclear localization of the plasmid DNA. This study emphasizes the need to engineer a plasmid able by itself to overcome the nuclear barrier. It also shows that while the first in vitro proof-ofconcepts are necessary when studying innovative vectors or plasmids, it is essential to quickly move to the most in vivo appropriate models since the underlying mechanisms of gene transfer may be very different between in vitro and in vivo models.

\section{Acknowledgements}

We are grateful to the Services Communs de Microscopie Confocale et de Cytométrie de Flux (IFR Alfred Jost, Paris). This research was supported by the Association Vaincre la Mucoviscidose and the Chancellerie des Universités de Paris.

\section{References}

[1] G.F. Lemkine, B.A. Demeneix, Polyethylenimines for in vivo gene delivery, Curr. Opin. Mol. Ther. 3 (2001) 178-182.

[2] B. Demeneix, J.P. Behr, Polyethylenimine (PEI), Adv. Genet. 53 (2005) 217-230.

[3] O. Boussif, F. Lezoualc'h, M.A. Zanta, M.D. Mergny, D. Scherman, B. Demeneix, J.P. Behr, A versatile vector for gene and oligonucleotide transfer into cells in culture and in vivo: polyethylenimine, Proc. Natl. Acad. Sci. U. S. A. 92 (1995) 7297-7301.

[4] N.D. Sonawane, F.C. Szoka Jr., A.S. Verkman, Chloride accumulation and swelling in endosomes enhances DNA transfer by polyamine-DNA polyplexes, J. Biol. Chem. 278 (2003) 44826-44831.

[5] A. Bragonzi, G. Dina, A. Villa, G. Calori, A. Biffi, C. Bordignon, B.M. Assael, M. Conese, Biodistribution and transgene expression with nonviral cationic vector/DNA complexes in the lungs, Gene Ther. 7 (2000) 1753-1760.

[6] J.W. Wiseman, C.A. Goddard, D. McLelland, W.H. Colledge, A comparison of linear and branched polyethylenimine (PEI) with DCChol/DOPE liposomes for gene delivery to epithelial cells in vitro and in vivo, Gene Ther. 10 (2003) 1654-1662.

[7] D. Goula, C. Benoist, S. Mantero, G. Merlo, G. Levi, B.A. Demeneix, Polyethylenimine-based intravenous delivery of transgenes to mouse lung, Gene Ther. 5 (1998) 1291-1295.

[8] C.L. Densmore, F.M. Orson, B. Xu, B.M. Kinsey, J.C. Waldrep, P. Hua, B. Bhogal, V. Knight, Aerosol delivery of robust polyethyleneimine-DNA complexes for gene therapy and genetic immunization, Mol. Ther. 1 (2000) 180-188.

[9] C. Rudolph, J. Lausier, S. Naundorf, R.H. Muller, J. Rosenecker, In vivo gene delivery to the lung using polyethylenimine and fractured polyamidoamine dendrimers, J. Gene Med. 2 (2000) 269-278.

[10] A. Gautam, C.L. Densmore, E. Golunski, B. Xu, J.C. Waldrep, Transgene expression in mouse airway epithelium by aerosol gene therapy with PEI-DNA complexes, Mol. Ther. 3 (2001) 551-556.

[11] A. Kichler, M. Chillon, C. Leborgne, O. Danos, B. Frisch, Intranasal gene delivery with a polyethylenimine-PEG conjugate, J. Control. Release 81 (2002) 379-388.

[12] C. Rudolph, A. Ortiz, U. Schillinger, J. Jauernig, C. Plank, J. Rosenecker, Methodological optimization of polyethylenimine (PEI)-based gene delivery to the lungs of mice via aerosol application, J. Gene Med. 7 (2005) 59-66.

[13] G.J. Jeong, H.M. Byun, J.M. Kim, H. Yoon, H.G. Choi, W.K. Kim, S.J. Kim, Y.K. Oh, Biodistribution and tissue expression kinetics of plasmid DNA complexed with 
polyethylenimines of different molecular weight and structure, J. Control. Release 118 (2007) $118-125$

[14] I. Fajac, S. Grosse, A.C. Roche, M. Monsigny, Cystic fibrosis gene therapy: key questions and prospects, Curr. Pediatr. Rev. 2 (2006) 99-105.

[15] S.Y. Wong, J.M. Pelet, Polymer systems for gene delivery-Past, present, and future, Prog. Polym. Sci. 32 (2007) 799-837.

[16] I. Fajac, G. Thévenot, L. Bédouet, C. Danel, M. Riquet, M. Merten, C. Figarella, J. Dall'Ava-Santucci, M. Monsigny, P. Briand, Uptake of plasmid/glycosylated polymer complexes and gene transfer efficiency in differentiated airway epithelial cells, J. Gene Med. 5 (2003) 38-48.

[17] S. Grosse, Y. Aron, I. Honore, G. Thevenot, C. Danel, A.C. Roche, M. Monsigny, I. Fajac, Lactosylated polyethylenimine for gene transfer into airway epithelial cells: role of the sugar moiety in cell delivery and intracellular trafficking of the complexes, J. Gene Med. 6 (2004) 345-356.

[18] J.R. de Wet, K.V. Wood, M. DeLuca, D. Helinski, S. Subramani, Firefly luciferase gene: structure and expression in mammalian cells, Mol. Cell. Biol. 7 (1987) 725-737.

[19] H.D. Hill, J.G. Straka, Protein determination using bicinchoninic acid in the presence of sulfhydryl reagents, Anal. Biochem. 170 (1988) 203-208.

[20] A. Bragonzi, M. Conese, Non-viral approach toward gene therapy of cystic fibrosis lung disease, Curr. Gene Ther. 2 (2002) 295-305.

[21] L.A. Davies, C. Seguela, A. Varathalingam, S.H. Cheng, S.C. Hyde, D.R. Gill, Identification of transfected cell types following non-viral gene transfer to the murine lung, J. Gene Med. 9 (2007) 184-196.
[22] C. Rudolph, U. Schillinger, A. Ortiz, C. Plank, M.M. Golas, B. Sander, H. Stark, J. Rosenecker, Aerosolized nanogram quantities of plasmid DNA mediate highly efficient gene delivery to mouse airway epithelium, Mol. Ther. 12 (2005) 493-501.

[23] S. Grosse, Y. Aron, G. Thevenot, D. Francois, M. Monsigny, I. Fajac, Potocytosis and cellular exit of complexes as cellular pathways for gene delivery by polycations, J. Gene Med. 7 (2005) 1275-1286.

[24] W.T. Godbey, K.K. Wu, A.G. Mikos, Tracking the intracellular path of poly (ethylenimine)/DNA complexes for gene delivery, Proc. Natl. Acad. Sci. U. S. A. 96 (1999) 5177-5181.

[25] T. Bieber, W. Meissner, S. Kostin, A. Niemann, H.P. Elsasser, Intracellular route and transcriptional competence of polyethylenimine-DNA complexes, J. Control. Release 82 (2002) 441-454.

[26] K. Itaka, A. Harada, Y. Yamasaki, K. Nakamura, H. Kawaguchi, K. Kataoka, In situ single cell observation by fluorescence resonance energy transfer reveals fast intra-cytoplasmic delivery and easy release of plasmid DNA complexed with linear polyethylenimine, J. Gene Med. 6 (2004) 76-84.

[27] S. Mishra, P. Webster, M.E. Davis, PEGylation significantly affects cellular uptake and intracellular trafficking of non-viral gene delivery particles, Eur. J. Cell Biol. 83 (2004) 97-111. 